\title{
Archivo, Testimonios y Memorias en Uruguay
}

\author{
Archive, Testimonials and Memories in Uruguay \\ Martina Eva Garcia \\ Universidad Nacional de Buenos Aires, Argentina \\ Universidad de la República (Montevideo), Uruguay \\ martinaevagarcia@gmail.com
}

\section{Resumen:}

En el siguiente trabajo me propongo describir y analizar brevemente, desde mi experiencia como entrevistadora, algunos aspectos del Archivo Oral de la Memoria; dando cuenta de su contexto de creación y su vinculación con el proyecto de Sitios de Memoria. Asimismo a través de un momento y un recorte de la extensa noción desarrollada por Pierre Nora analizo el archivo oral como Lugar de Memoria. Dada la imposibilidad de dar una definición acabada de esta categoría elegí tomar dos elementos que se mantienen en sus redefiniciones: La dimensión simbólica de los Lugares de Memoria y la Voluntad de Memoria de los mismos. Los testimonios que este archivo atesora - en tanto pasaje de lo privado a lo público - otorgan el carácter simbólico a este lugar de memoria, y se configuran como hecho político.

Palabras Clave: Archivo Oral, Memorias, Testimonios, Lugar de Memoria.

\section{ABstract:}

The following research paper has the aim of describe and analize briefly, from my experience as an interviewer, some aspects of the Oral Archive of Memory; giving account of its creation context and its link with the Memory Sites project. Also, through a moment and a cut of the extensive notion developed by Pierre Nora, I analyze the oral archive as a Memory Place. Considering the impossibility of contributing with a finished definition of this category, I chose to take two elements that remain in their redefinitions: The symbolic dimension of the Places of Memory and the Will of Memory. The testimonies that this archive treasures - as a passage from the private to the public - give the symbolic character to this place of memory, and are configured as a political fact.

KeYwords: Oral File, Memories, Testimonials, Memory Place.

\section{INTRODUCCIÓN}

El siguiente trabajo surge como necesidad de reflexionar sobre la propia práctica de entrevistadora en este archivo. Si bien existen muchas diferencias entre el trabajo de campo etnográfico y la entrevista etnográfica, me resulta imposible escindir "la mirada antropológica" en el quehacer de la entrevistas, por lo tanto, es a partir de mi propia experiencia como entrevistadora y estudiante de antropología, que tomaré algunos fragmentos de entrevista y momentos de la interacción con los/as entrevistados/as que me resultaron sumamente significativos para su análisis.

El Archivo Oral de la Memoria está compuesto por más de 50 de testimonios de sobrevivientes de Centros Clandestinos de Detención y Tortura (CCDyT), exiliados, presos políticos y familiares que condensan experiencias de militancia político-social, de persecución y represión por parte del Estado y violaciones a los derechos humanos, enmarcadas (en el sentido de Halbwach) en los principales procesos sociales, políticos e ideológicos de la segunda mitad del siglo XX. Aquí nos centraremos en dar cuenta del valor de estos testimonios, como un relato que pasa de lo privado a lo público, pasando de la memoria más íntima a la esfera pública. 
"Toda narrativa del pasado implica una selección. La memoria es selectiva; la memoria total es imposible." (Jelin, 2001, p. 10). Todo testimonio, en tanto narración sobre el pasado se encuentra plagado de silencios y olvidos, los cuales tienen diferentes significados, usos y sentidos.

A lo largo de la historia las sociedades reflexionan sobre su pasado y atesoran en la memoria algunos hechos de su pasado reciente, como afirma Jelin retomando a Moliner: "La memoria, en tanto «facultad psíquica con la que se recuerda» o la «capacidad, mayor o menor, para recordar» (Moliner, 1998, p. 318) (recordar: «retener cosas en la mente»), ha intrigado desde siempre a la humanidad." (Jelin, 2001, p. 2).

Particularmente en sociedades donde se han vivido procesos de violencia política, las huellas del pasado quedan muy marcadas. En muy pocas ocasiones encontramos una unanimidad en términos memorísticos y de interpretación de esos pasados, como afirma Joel Candau rara vez los recuerdos se mueven al mismo ritmo, por lo general las memorias se enfrentan y actualmente mucho más, dado que hay cada vez más grupos e individuos que hacen valer sus pretensiones de hacer memoria. En relación con lo anterior, el historiador Pierre Nora en una nota para el Diario la Nación afirma que “(...) apareció una vida mediática densa, que contribuyó a crear una forma de memoria colectiva, independiente del poder puramente científico. Las tragedias del siglo XX contribuyeron, en gran medida, a democratizar la historia, es decir, a hacerla vivir. El hombre comenzó a sentir que lo que vivía era la historia, contrariamente a lo que sucedía en las sociedades campesinas tradicionales"1 - a "tragedias" agregaría: genocidios y violencia política -.

Ahora bien, por qué hablamos de grupos que hacen valer sus memorias si quienes recordamos somos los individuos. Está discusión acerca la relación entre memorias individuales y colectivas posee una larga tradición en los estudios sociales de memoria. No es mi intención aquí hacer un "estado del arte" sino destacar algunos desarrollos conceptuales que me resultan significativos para este trabajo.

Para comprender los procesos sociales de memorias, la noción de "marcos sociales" desarrollada por Maurice Halbwachs cobra vital importancia. El trabajo de Halbwachs intenta demostrar que las memorias individuales siempre se despliegan en un marco social, siempre que recordamos lo hacemos en común con otros, “(...) sólo podemos recordar cuando es posible recuperar la posición de los acontecimientos pasados en los marcos de la memoria colectiva (...)” (Halbwachs, 1992, p. 172). Los recuerdos de otros y los códigos culturales compartidos ayudan y se imprimen en los recuerdos individuales y personales, el grupo le brinda los instrumentos para la reconstrucción de su pasado mediante fechas, palabras, rituales y conmemoraciones. De acuerdo con Elizabeth Jelin, el pasaje de lo individual a lo colectivo se impone cuando pensamos procesos de memorias, ya que los mismos no ocurren en individuos aislados sino en seres humanos insertos en un entramado de relaciones sociales, grupos, redes culturales e instituciones; de esta manera se hace imposible pensar los recuerdos o las huellas del pasados por fuera de estos contextos. Por lo tanto, las memorias individuales siempre son enmarcadas socialmente. En definitiva, en la memoria que "por naturaleza, es afectiva, emotiva, abierta a todas las transformaciones, inconsciente de sus sucesivas transformaciones, vulnerable a toda manipulación" (Nora, 2018), la selectividad que opera no es más que el resultado de un ordenamiento del pasado en función de las visiones del mundo, de los símbolos y representaciones del grupo. Siguiendo la línea de Halbwachs, para que la memoria de otros realice su tarea de reforzar nuestros recuerdos, es preciso que esos recuerdos grupales tengan relación con los hechos de mi pasado. Si bien cada uno de nosotros pertenecemos a un grupo amplio que es el país o la nación, los grupos intermedios actúan "mucho más directamente sobre la vida y el pensamiento de sus miembros” que la nación, cuya historia sólo tiene algunos puntos de contacto con la historia de los individuos (Halbwachs, 1968).

Michael Pollak retomando el trabajo de Halbwachs, introduce una perspectiva que intenta ser superadora de la herencia durkheimiana, y afirma que el análisis debe centrarse en cómo los hechos sociales se transforman en cosas, es decir, quiénes y cómo intervienen en ese proceso. En consecuencia, el foco va a estar puesto sobre los agentes y procesos que intervienen en la constitución y formalización de las memorias. De esta manera, las memorias entran en disputas y la historia oral pone el centro de atención de sus análisis en las minorías, lo que el autor denomina las memorias subterráneas. Las memorias de los excluidos y los marginados que 
se oponen y ponen en tensión la "memoria oficial". En interesante destacar que el vínculo entre memoria oficial y memorias subalternas al igual que la significación del pasado sobre el silencio, no debe ser pensado siempre en terminados de dominador y sociedad civil - Estado o Gobierno / pueblo- sino que muchas veces estas tensiones se hacen presentes entre grupos minoritarios y la sociedad general. En el Cono sur por ejemplo los procesos de transición post-dictatoriales no fueron fáciles, muchos de los actores políticos no veían las violaciones a los derechos humanos como prioritarios o urgentes. Coexistían quienes estaban dispuestos a postergar la cuestión; aquellos a quienes no les preocupaba el tema; los que impulsaban el olvido y los que reivindicaban la actuación de los militares justificando las violaciones. Por lo que, quienes querían castigar a los culpables eran una voz entre muchas otras (Jelin, 2008).

Puntualmente en Uruguay, primero en 1989 y luego en 2009 se plebiscitó la anulación de Ley 15.848 de Caducidad de la Pretensión Punitiva del Estado. En ambas oportunidades la mayoría de la sociedad uruguaya votó a favor de la NO anulación de dicha ley, que desde 1986 ampara a quienes cometieron violaciones a los derechos humanos durante la dictadura.

El pasado ha desaparecido, no es posible exhibirlo tal cual es sino a través de las "huellas" que ese pasado ha dejado para que nos acerquemos a él. Como pruebas de existencia, esas huellas se nos hacen presentes tanto en dimensiones discursivas como materiales. La memoria es construida a través de las historias y experiencias vividas por los sujetos que recuerdan y reconstruyen esos materiales del pasado siempre a partir del uso de datos del presente y con expectativas de futuro.

Las prácticas discursivas que narran las experiencias e historias pasadas se identifican como memorias de lo sucedido. La memoria no es entonces algo dado, por lo que debemos centrar la atención en las dinámicas, prestando atención las tensiones y luchas, que suponen relaciones de poder. La memoria es analizada y comprendida en términos de disputa, de valoración, de estudio, en torno al cual se despliegan modos de hacer hacer y hacer decir en el presente. "Con la memoria, (...), la marca del antes y el después se deposita en la cosa evocada" (Ricoeur, 2000, p. 5)

Por lo tanto, las memorias debe ser entendida como algo más que meros datos "dados", es preciso comprenderlas como una construcción social, objeto de disputas, conflictos y luchas y permeable a los cambios históricos y sociales. Dando lugar a los diferentes actores sociales y negociaciones en torno a los sentidos del pasado que nos permite dar cuenta de las relaciones de poder implicadas en los procesos de construcción de las memorias (Jelin, 2001; Guglielmucci, 2013).

\section{Contexto de Creación del Archivo Oral de la Memoria}

\section{El Museo}

En el año 2006 es creado Centro Cultural Museo de la Memoria (MUME), y abierto al público un año después, en diciembre de 2007. Esta institución depende de la Dirección de Cultura de la Intendencia de Montevideo, tanto en su fundamentación del 2006 como en su página institucional se explicita que su surgimiento responde a la necesidad urgente de simbolizar contundentemente la historia del golpe de Estado en el país para que nunca más se vuelva a repetir ${ }^{2}$. Su "misión" se define como la creación de un espacio para la promoción de los Derechos Humanos y la Memoria de la lucha por la Libertad, la Democracia y la Justicia Social.

Las líneas y áreas de trabajo del museo son las siguientes: Departamento educativo que coordina las visitas guiadas y talleres orientados a instituciones educativas de nivel primario, secundario y terciario. El área de archivo donde se preservan diferentes colecciones documentales y materiales que fueron donadas o cedidas a préstamos al museo, y que son exhibidas en las salas. En esta área funciona también el Archivo Oral de la Memoria. Como "Centro Cultural” el museo cuenta también con una agenda artístico-cultural que consta 
de intervenciones, conciertos, teatro y exposiciones temporales. A la vez que funciona como sede y promotor de seminarios de formación docentes, mesas redondas, conferencias y simposios.

El equipo del museo esta integrado por su Director, Elbio Ferrario, las coordinadoras del área educativa y de archivo, dos investigadores, una capataza, una administrativa, dos asistentes de sala, una montajista, dos asistentes de atención al público, un jardinero, un técnico infógrafo, un vigilante, una pasante, cuatro guías y siete talleristas.

\section{Los Sitios}

En el año 2015 el MUME, el Espacio para la Memoria Quica Salvia (IMC), la Asociación de Amigas y Amigos del MUME, y la Fundación Zelmar Michelini, comenzaron a trabajar en proyectos que generen la visualización de dos Centros Clandestinos de Detención y Tortura (CCDyT) que funcionaron durante la última dictadura: "300 Carlos" y "Los Vagones". Y en la redacción y su posible aprobación de un proyecto de Ley de Sitios de Memoria. Con el asesoramiento de Memoria Abierta (Argentina) se realizaron seminarios, encuentros y talleres, tendientes a definir "las cinco preservaciones relacionadas en un proyecto de actuación integral de Sitios de Memoria: 1) Preservación Patrimonial; 2) Preservación de la Comunidad; 3) Preservación Arquitectónica, 4) Preservación Arqueológica; 5) Preservación de la Memoria." (Documento Archivo Oral de la Memoria, 2018)

"300 Carlos"- "infierno Grande" es un sitio tutelado por la Justicia, ubicado dentro de un predio militar, el cual comprende el Servicio de Material y Armamento (SMA) y el Batallón 13. Entre 1975 y 1977 funcionó como CCDyT creado por Organismo Coordinador de Operaciones Antisubversivas (OCOA) de la División de Ejército $\mathrm{N}^{\circ} 1$ con el conocimiento del Servicio de Información y Defensa (SID). En 2005 fue recuperado un enterramiento primario (López Mazz et al. 2007), el que correspondió a un adulto masculino, en un fosa rectangular excavada en el suelo natural, presentando fragmentos de cal y cubierta por una losa de hormigón. Los restos recuperados fueron identificados por análisis de ADN como Fernando Miranda, de 56 años de edad al momento de su desaparición, el 30 de noviembre de 1975 (GIAF 2013-14 42). Actualmente se continúan realizando excavaciones en el predio del Batallón 13.

Este sitio formó parte de un circuito de CCDyT, junto a la casona de Punta Gorda ("Infierno Chico") y la ex cárcel del pueblo, denominado "El circuito de los 300 Carlos".

El 27 de Junio de 2016 se realizó, en el marco de lo dispuesto por los artículos 7 y 8 de la Ley No 18.596 de Reconocimiento y Reparación a las víctimas de la actuación ilegítima del Estado, la colocación de dos placas conmemorativas en el predio de SMA y el Batallón 13.

El Sitio "Los Vagones" ubicado en el Barrio Olímpico de la Ciudad de Canelones operó como CCDyT a partir de septiembre del año 1975 y forman parte de un circuito de represión que estuvo compuesto por otro sitio de vagones que estaba localizado cercano a lo que era la Escuela de Policía. En los años posteriores tuvo otros usos y fue sumamente invisibilizado, en su mayoría los habitantes de la ciudad desconocen su existencia. El 19 de mayo de 2018, la Intendencia de Canelones y la Asociación Ágora - Identidad, Derechos Humanos y Memoria Canaria- realizaron un acto con motivo de la señalización del Sitio de Memoria "Los Vagones". Como todo proceso social, el proyecto de Sitios no escapó a la lógica propia de las dinámicas grupales, políticas e institucionales. De esta manera se fueron delineando dos equipos de trabajo en torno a cada uno de los sitios. Durante el 2017 se conformó una comisión de trabajo para la actuación en el sitio, integrada por: MUME, la Asociación de Amigos y Amigas del MUME, el Municipio d, el Municipio g, el Complejo Municipal SACUDE, el Centro Cívico Luisa Cuesta, el Centro Comunal Zonal $N^{\circ} 11$, el Centro Comunal Zonal N - 13, Madres y Familiares de Detenidos Desaparecidos, la Asociación de Amigas y Amigos del MUME, el Consejo Vecinal 11, el Consejo Vecinal 13, la Agrupación UTE - AUTE, la Fundación Zelmar Michelini y sobrevivientes del "300 Carlos" Por otro, en el sitio conocido como "Los Vagones" la Asociación Civil 
AGORA, el Espacio Para la Memoria y los DDHH “Quica Salvia” dependiente de Intendencia de Canelones y sobrevivientes del sitio comenzaron a trabajar en la señalización y preservación del mismo.

Tanto el "300 Carlos" como "Los Vagones" fueron utilizados como CCDyT en la "Operación Morgan", este operativo represivo contra los militantes del Partido Comunista Uruguayo (PCU) y el Partido por la Victoria del Pueblo (PVP) se desarrolló en Argentina y Uruguay hasta junio de 1976. El nombre "Morgan" alude al clásico pirata británico, ya que el objetivo estratégico era desmantelar la estructura financiera, el aparato armado y de propaganda del PCU. Las acciones represivas fueron implementadas por Organismo Coordinador de Operaciones Antisubversivas (OCOA) (Investigación histórica, tomo III; 28).

\section{El Archivo Oral}

El Archivo Oral de la Memoria surge entonces como una iniciativa complementaria del proyecto de Sitios, como afirma uno de los integrantes "La importancia del Archivo Oral dentro de este proyecto es que los Sitios, muestre realmente lo que ocurrió en aquellos lugares. Porque efectivamente, la sociedad conoce de manera relativa que en este país hubieron torturas, hubo persecución, hubo homicidio político...hubieron desaparecidos"3.

El proyecto del archivo se configuró como una forma de "hacer hablar" esos lugares. En definitiva, de lo se trata es de considerar las memorias en sus dimensiones discursivas y materiales, los restos físicos de ese pasado cobran significación cuando son relacionadas con los discursos de quienes estuvieron allí, de los testigos. Como todo proceso social dinámico el archivo oral fue mutando en sus objetivos y alcances, y si bien nació con el objetivo de acompañar la iniciativa de sitios, luego se convirtió en un proyecto de mayor alcance. De esta manera, las entrevistas realizadas a los sobrevivientes y familiares del sitio "300 Carlos" dejaron de conformar el acervo completo del archivo para conformarse como una serie más entre otras previstas por el equipo. "El Archivo Oral de la Memoria -Uruguay, creado por el MUME y la Asociación de Amigas y Amigos del MUME, comienza su tarea con la conformación el Archivo de Testimonios del Sitio "300 Carlos”. (...) Pero los objetivos y alcance de este Archivo Oral terminaron siendo más amplios que el archivo referido a un sitio, abarcando al conjunto de las luchas políticas en Uruguay desde fines de la década de 1950, y los cambios sociales, políticos y culturales que se produjeron. (...)”. (Documento Archivo Oral de la Memoria - Uruguay, 2018:8). Para la construcción de este archivo se adoptó la metodología desarrollada por Memoria Abierta (Argentina), quienes mediante talleres, el aporte de profesionales, y consultores de archivo transmitieron su experiencia y monitorearon la experiencia uruguaya. Se compone de registros audiovisuales de entrevistas narrativas testimoniales, lo que permite integrar la gestualidad, la corporalidad, el movimiento, la espacialidad, los silencios, el volumen sonoro, etc. incorporando otras dimensiones discursivas, el mismo no se edita - excepto que se solicitado por el entrevistado-, ni se transcribe. Si el entrevistado solamente aceptara un registro de audio, se accederá a esa modalidad de entrevista.

El Archivo de testimonios se propone generar un espacio de formación, documentación, producción, preservación y sistematización de documentos sobre nuestro pasado reciente -historia presente, a través de testimonios personales donde los relatos den cuenta de la experiencia de las personas y de hechos significativos del período. La construcción del archivo atenderá a que el conjunto de testimonio de cuenta de la existencia de puntos de vista diferentes sobre la temática en cuestión, así como su carácter de asunto público. El trabajo comprende un conjunto de acciones que son anteriores y posteriores al registro del testimonio. Éstas comienzan en el momento en que se definen los nombres de las personas con quienes se va a tomar contacto para la entrevista. El coordinador contacta a la persona a fin de transmitir la misión y los objetivos de las entrevistas, para luego asignar a un entrevistador o a una entrevistadora, de acuerdo a variables evaluadas por la coordinadora. Luego se realiza el "primer contacto" entre el/la entrevistado/a y el/la entrevistador/a, donde se pautan las fechas de entrevistas y los temas a tratar, más adelante volveremos sobre el primer encuentro. 
Actualmente cuenta con casi setenta entrevistas realizadas, y se han comenzado a diversificar las series ${ }^{4}$ que conforman el acervo: CCDyT "La Tablada”; "Familiares" y "Segunda Generación”. El 7 de noviembre de 2017 se realizó en la Intendencia de Montevideo la presentación oficial del Archivo5. En la página web del museo se encuentran a disposición la lista de "microresumenes" de los testimonios disponibles en el Archivo Oral (nombre y apellido del testimoniante, organización política o gremial a la cual pertenecía, fechas y lugares de detención). Para la consulta pública de las entrevistas es necesario completar un formulario y enviarlo al correo institucional.

\section{El Archivo como "Lugar de Memoria”}

Luego de más de veinte años de aparición del concepto "lugares de memoria" desarrollado por Pierre Nora, se han escrito ya multiplicidad de libros y artículos haciendo uso de esta noción. Sin embargo, muchos autores y el mismo Nora se preguntan acerca de su aplicabilidad fuera de Francia y en el análisis de los pasados recientes. Sin ánimos de hacer un análisis exhaustivo ni cernir este trabajo a la exclusiva aplicación de esta noción, hay algunos elementos que resultan interesantes para intentar pensar en Archivo Oral de la Memoria - Uruguay como un "lugar de memoria".

No es posible hacer una transcripción exacta de esta definición dada la plasticidad de la misma, y las múltiples modificaciones que el autor fue operando a lo largo de los años sobre este concepto. Josefina Cuesta Bustillo se pregunta si esta noción no debe ser comprendida más como un método, que como una categoría analítica:

Su autonomía del molde en el que le vierte su creador le hace correr el riesgo de diluirse, de ahí el empeño de Nora en redefinirle continuamente. Plasticidad y elasticidad que permiten preguntarse si no podría ser más un método que un concepto de contornos definitivamente definidos o una nueva forma de aproximación y de análisis a la memoria. (Cuesta Bustillo, 1998, p. 218)

En su primera versión el autor los define como los lugares donde se cristaliza y se refugia la memoria, donde se ancla, condensa y expresa el capital agotado de la memoria colectiva. Para considerarlos como tales deben ser considerados en los tres sentidos de la palabra: material, simbólico y funcional; en grados diferentes pero siempre presentes. Asimismo, aquello que los convierte en lugares de memoria es un juego de la memoria y la historia, una interacción de ambos factores que permite su sobre determinación recíproca. Para que ellos existan es necesario que exista la voluntad de memoria, si ella falta, serán lugares de historia (Nora, 1984). El concepto se va ampliando a «toda unidad significativa, de orden material o ideal, de la cual la voluntad de los hombres o el trabajo del tiempo ha hecho un elemento simbólico del patrimonio memorial de cualquier comunidad» (Nora, 1992, p. 20). Existen dos elementos que se mantienen invariables en la redefiniciones del autor: la dimensión simbólica de los lugares de memoria y la voluntad de memoria. Respecto a la voluntad de memoria la distinción trazada por Eugenia Allier Montaño resulta esclarecedora. Cuando Pierre Nora habla de voluntad de los hombres o del trabajo del tiempo es posible incluir dentro de la misma tanto lugares que pueden ser entendidos como puntos de cristalización de la memoria, como aquellos construidos por los diferentes actores o grupos con la expresa voluntad de "rescatar" la memoria. Es decir, en algunos casos, los lugares de memoria poseen en sí mismos voluntad de memoria sin necesidad de que se les otorgue desde afuera, o en todo caso les es otorgada con el tiempo. Y otros son creados con voluntad expresa de que se conviertan en artefactos que contribuyan a la memoria (Allier Montaño, 2008).

El archivo oral es en sí una construcción, un artefacto creado y diseñado por voluntad de hombres y mujeres con objetivos académicos, políticos e ideológicos determinados. No podemos pensar el archivo oral como lugar o espacio que emana significados por su propia materialidad, sino que lo convierte en un lugar de memoria es justamente la voluntad de memoria que contiene desde su surgimiento. Posee la voluntad expresa de "rescatar" las memorias de "luchas políticas en Uruguay desde fines de la década de 1950, los 
cambios sociales, políticos y culturales que dieron lugar a la movilización social que cuestionó el orden existente, y la represión que dio lugar a las violaciones de los derechos humanos, la dictadura y el terrorismo de Estado." (Documento Archivo Oral de la Memoria- Uruguay, 2018).

Con "los lugares de memoria" Nora establece un pasaje del acontecimiento a lo simbólico en el estudio de la historia, poniendo el énfasis en el símbolo, y no ya en el acontecimiento. De esta manera, cobran relevancia las representaciones presentes de esos acontecimientos y juegan un rol central los actores. El valor simbólico de los lugares de memorias va a estar dado por las representaciones de las huellas del pasado, las significaciones de lo acontecido. Por lo tanto el valor simbólico del Archivo Oral de la Memoria está condensado en los testimonios que atesora. Como afirma Pierre Nora, estos lugares no se reducen a monumentos o acontecimientos memorables, a objetos puramente materiales. "Les lieux de mémorie" es una noción abstracta, destinada a desentrañar la dimensión rememoradora de los objetos que pueden ser materiales pero sobre todo inmateriales. Los testimonios sobre el pasado son siempre una representación desde el presente de los hechos acontecidos. Implican un volver hacia atrás desde un hoy, la memoria aparece como una recreación del pasado desde de los dilemas, preguntas y demandas del presente. Retomando a Achugar, los lugares de memorias deben ser entendidos como enunciaciones, y es necesario poner el foco sobre el horizonte político e ideológico en el que se construyen esas enunciaciones (Achugar, 2003).

Centrándonos en los testimonios de los detenidos del CCDyT “300 Carlos" - los cuales conforman la primera serie del Archivo Oral y representan el mayor porcentaje de entrevistas realizadas-, esto cobra total relevancia. En primer lugar, como señalamos más arriba, el “300 Carlos” aún continúa siendo utilizado y funcionando dentro del predio militar. Si bien dentro de las políticas de reparación material y simbólica del Ministerio de Educación y Cultura se colocó una placa conmemorativa, la realidad es que los habitantes de los barrios aledaños en su mayoría desconocen lo sucedido allí dentro. Por otro lado, la causa que investiga los delitos de tortura, privación de libertad, violación, lesiones personales, amenazas, atentado a la libertad personal por funcionario público de una cárcel y abuso de autoridad contra los detenidos, ocurridos en el "300 Carlos", iniciada en el año 2011 aún no ha tenido resoluciones significativas. Continuando con las políticas de reparación, la Ley $\mathrm{N}^{\circ} 18596$ establece que el Estado uruguayo, a través de una Comisión Especial expedirá un documento que acredite la condición de víctima y la responsabilidad institucional que le cabe al haber afectado la dignidad humana de quienes hubiesen permanecido detenidos por más de seis meses por motivos políticos, ideológicos o gremiales, sin procesamiento en el país o en el extranjero bajo el control o la participación de agentes del Estado o quienes sin serlo, hubiesen contado con su autorización, apoyo o aquiescencia ${ }^{7}$. Por lo tanto, para ser "acreditados" como víctimas, los detenidos debieron haber estado en esa condición al menos por seis meses. Mientras que el tiempo estimado que los detenidos en forma clandestina e ilegal que pasaron por el "300 Carlos" y otros centros CCDyT, estaban alrededor de dos meses - muchos de ellos volvieron a ser trasladados desde los cuarteles o el Penal de Libertad-.

Esto nos permite preguntarnos por el lugar del testimonio en relación a la denuncia de la represión, la detención ilegal, la tortura y la violación de los derechos humanos y cuál es actualmente y a futuro, su valor en torno en términos simbólicos y judiciales. "Así, pese a la imposibilidad de tener acceso directo a la documentación sobre violaciones a los Derechos Humanos, los crímenes perpetrados por el Estado han podido conocerse a través de los testimonios de quienes los sufrieron. (Bacci, Oberti, Skura 2012).

\section{Archivo como reservorio y conservación de testimonios: El valor del Testimonio}

Retomando la noción desarrollada por la antropóloga Susana Skura definimos testimonio como:

(...) Un relato que pasa de lo privado a lo público, de la memoria personal a la denuncia y el reclamo, volviéndose un hecho político. El testimonio es una forma de relato que no consiste solamente en un intercambio entre un sujeto que requiere información y otro que la brinda, (...) sino que es, ante todo, una situación de transmisión, una búsqueda de salir del soliloquio para compartir ese relato en un espacio público, y en ese proceso el discurso se vuelve testimonio. Lo que sucederá al momento 
del registro, lo que será dicho y lo silenciado tienen un origen en tanto relato que comienza a definirse mucho antes del encuentro, de modo que nos subimos a ese devenir de la vida y de la memoria de los entrevistados, y ese proceso continuará aún después que demos por concluido el encuentro y nos despidamos.” (Skura, 2017, p. 147).

Michael Pollak hace mención de la vivacidad de los recuerdos, de los "no dichos” y su permanencia en el tiempo, estos recuerdos dice el autor son transmitidos en el marco familiar, en asociaciones, etc. Son recuerdos prohibidos, indecibles o vergonzosos que celosamente se guardan en estructuras de comunicación informales, pasando desapercibidos por la sociedad en general. El testimonio se transforma así, en el pasaje de lo esfera íntima a lo público. Al momento de la entrevista sólo estamos el/la que entrevista, el camarógrafo/a y el/ la entrevistado/a, sin embargo ese universo dialógico trasciende ese encuentro. No sólo por el hecho de ser el testimonio un documento público libre para la consulta, sino porque la narración se construye desde el supuesto de una audiencia. Quien testimonia, también lo hace pensando en un potencial oyente.

Omar Mir estaba dando su opinión respecto a las políticas de memoria y derechos humanos del Frente Amplio como Gobierno, y en medio del relato comenzó a mirar la cámara y a señalarla con su mano, le estaba hablando a la cámara:

¡Mira lo que les estoy pidiendo! A los militares, a los que aún quedan vivos, los que participaron en la tortura ¡Que ellos me conocen, yo no los conozco! que saben cómo me dieron, que a otros les dieron más iy a otros los hicieron desaparecer! ¡Qué no tuvieron la valentía de decir: 'sí los matamos defendiendo la Patria!'. ¡Los escondieron! (Omar Mir, entrevistado en Septiembre de 2017).

La autoridad del testimonio no consiste en garantizar la veracidad de lo que se enuncia, sino en la reformulación. Pierre Nora afirma que la memoria está abierta a la dialéctica del recuerdo y la amnesia, inconsciente de sus deformaciones sucesivas, vulnerable a todas las utilizaciones y manipulaciones, susceptible de largas latencias y de súbitas revitalizaciones. El testimonio evoca una memoria que actualiza el recuerdo, lo transforma y lo representa en rigor de un presente determinado. El testimonio es, entonces, una forma efectiva de coadyuvar a que discursos que se hallaban en la esfera íntima tengan lugar. Es necesario resaltar, como bien lo afirma Jelin en su trabajo “¿De qué hablamos cuando hablamos de Memorias?”, que el poder de las palabras no está dado en las palabras mismas, la memoria - como construcción social narrativa- implica estudiar las propiedades de quien narra y de las instituciones que otorgan o dan poder. Es necesario tomar en cuenta los procesos de construcción del reconocimiento legítimo. "La recepción de palabras y actos no es un proceso pasivo sino, por el contrario, un acto de reconocimiento hacia quien realiza la transmisión” (Hassoun, 1996 en Jelin 2001).

\section{Memorias, Olvidos y Silencios}

Hablar de memoria es también hablar de olvidos y de silencios, existen multiplicidad de situaciones, usos, sentidos en los que se hacen presentes; toda acción requiere olvido, es imposible poder vivir sin olvidar (Nietzsche, 2000). La memoria es selectiva, pensar en una memoria total es imposible, siempre que hablamos de memoria es preciso hablar de olvidos y silencios. Los acontecimientos traumáticos acarrean grietas en la narración, ausencias en la memoria, la imposibilidad de dar sentido al acontecimiento pasado, de incorporarlo narrativamente, coexistiendo con su presencia persistente y su manifestación en síntomas, indica la presencia de trauma. De esta manera, el olvido no es ausencia o vacío, sino la presencia de esa ausencia, la representación de algo que estaba y ya no está (Jelin, 2001).

En una de mis primeras entrevistas a Maria Luisa Bategazzore "Marisa", reflexiona acerca de los eventos traumáticos vividos por las segundas generaciones: el exilio, el desexilio, las visitas al Penal de Libertad o a Punta de Rieles. Y, en relación al relato reciente de la violencia vivida por el hijo de un preso político por parte de los militares, ella nos dice: 
Todos callamos cosas. Yo soy consciente que hay un elemento de vergüenza en ciertas experiencias ¡De humillación!... que es lo que buscaban los milicos, es decir, el desnudar a la gente es un elemento de humillación, es en sí una humillación y una tortura. Tengo una imagen que es brutal, soy una persona de imágenes y hay imágenes que las tengo guardadas para la película que nunca voy a hacer. Y tengo una imagen de algunas veces que en el “300” bichaba, de los hombres desnudos en fila llevados a ducharse. Pelados, desnudos, parecía una escena de Auschwitz... una cosa muy golpeante. Entonces...Hay cosas que uno no olvida, pero tampoco las está contando todos los días... y hay cosas que sí, es sano olvidar también. Yo necesité olvidar muchísimas cosas... o por lo menos archivarlas... profundas. Uno tiene que hacerse una cierta cáscara, por eso dejar una terapia psicoanalítica te lleva tiempo, porque después de haber roto todas las cáscaras tenés que reconstruirte todas las cáscaras, no podes vivir... sin cáscaras. Y eso lleva su tiempo, un proceso de elaboración”. (Maria Luisa Bategazzore, entrevistada en Noviembre de 2016)

Más adelante Marisa narra el encuentro con “compañeros” al momento de la denuncia - en el marco de la Causa llevada adelante por la Jueza Mariana Motta -. En ese contexto de denunciar las tortura y la violencia que ejercieron sobre ellos en CCDyT, el hecho de conversar con otros/as que vivieron lo mismo le permitió rememorar cosas que creía olvidadas. Allí ella vuelve sobre los olvidos:

Hay muchas cosas que uno olvida, y otras que quiere olvidar. Yo te comenté que hice un ejercicio para olvidar, cada vez que algo me venía a la cabeza de todo lo que había pasado ahí me obligaba a bajar la cortina y ponerlo afuera. (..) Yo hice un ejercicio de olvido porque necesitaba sacarme esas cosas de la cabeza... para sobrevivir, para sobrellevar". (Maria Luisa Bategazzore, entrevistada en Noviembre de 2016).

Existe un primer tipo de olvido «necesario» para la sobrevivencia y el funcionamiento del sujeto individual afirma Jelin; como bien declara Primo Levi, el recuerdo de un trauma es en sí mismo traumático porque recordarlo duele, o al menos molesta: "quien ha sido herido tiende a rechazar el recuerdo para no renovar el dolor; quien ha herido arroja el recuerdo a lo más profundo para librarse de él, para aligerar su sentimiento de culpa." (Levi, 2000, p. 2). Este olvido resulta en alguna medida liberador, permite a muchas personas que atravesaron el horror, poder continuar su vida. Marisa hace referencia al ejercicio del olvido, el esfuerzo de dejar atrás el CCDyT para reconstruir su vida. En ambos fragmentos podemos ver cómo la entrevistada insiste en la idea de olvidar para fortalecerse y continuar. Las memorias traumáticas cristalizan también el momento de ruptura, estos eventos se vuelven memorables porque irrumpe el tránsito de la vida de las personas. Luego de la detención, nada fue igual, la tortura, la desaparición, penal o exilio. El olvido necesario o vital, es también el intento de sutura de esas historias interrumpidas. Pasados que parecían haber sido olvidados en forma definitiva, reaparecen y se actualizan producto de cambios en los marcos culturales, políticos y sociales que contribuyen a revisar y resignificar las huellas.

Mi primera entrevista fue a Fernando Funcasta, un militante del PVP, sociólogo y docente de nivel secundario; y con la ventaja de que su "memoria" no estaba derrotada por los años. Cuando le pregunté si había podido hablar de su secuestro y desaparición o de lo vivido dentro del 300 con sus hijos - que eran coetáneos a mí - me dijo que jamás había hablado de eso en los mismos términos que lo estaba haciendo conmigo, ni tampoco había sido entrevistado anteriormente. La segunda entrevistada: Maria Luisa Bategazzore, sólo había hablado de su secuestro y desaparición en el 300 Carlos con una amiga, que también había estado detenida allí, y que hacía poco tiempo había fallecido. La entrevistada había sido detenida junto a quien era su esposo en ese entonces

Entrevistada: "Nunca más lo hable, nunca más volví a hablar del tema hasta el retorno al Uruguay, que lo hablé con esta amiga, con (menciona el nombre), que había pasado por lo mismo. Ella falleció ya, y nunca más hablé.”

Entrevistadora: ¿Ni siquiera con tu esposo?

Entrevistada: "No, nunca hablamos. Nunca... Nunca... Nunca hablamos. Ni tampoco le conté de estas cosas a mi hijo. Sabe que estuvimos presos pero, nunca entré en detalles."

Podría continuar enumerando a gran parte de las personas que entrevisté, porque en su mayoría ninguno de ellos había hablado de su experiencia en el CCDyT. Resulta significativo que los entrevistados no hayan hablado con sus hijos e hijas, inclusive aquellos que sus hijos e hijas fueron testigos de su secuestro o durante 
años los visitaron en la cárcel. Siguiendo a Pollak esto podría responder a una necesidad de proteger a sus hijos de heridas sumamente dolorosas. "A esas razones políticas del silencio se agregan aquellas, personales, que consisten en querer evitar a los hijos crecer en el recuerdo de las heridas de los padres.” (Pollak, 2006, p. 6)

Quisiera resaltar la historia de un Roberto Calvete jubilado de la Administración Nacional de Usinas y Trasmisiones Eléctricas (UTE), un hombre que comenzó su vida política y militante a través de sindicato, cuando ya siendo un adulto de cerca de 30 años ingresó a UTE. A los pocos años comenzó a militar en el PCU, Roberto de ser un hombre de barrio "que no entendía nada de política", en pocos años era un militante sindical comprometido, afiliado al PCU y realizaba algunas "actividades clandestinas". Cuando lo detuvieron sus hijos eran grandes, algunos de ellos inclusive adolescentes y fueron testigos de secuestro. Roberto nunca había hablado de su paso por el 300, ni del Penal, ni de su militancia gremial ni partidaria. Al terminar la entrevista, nos agradeció por poder transmitir su historia.

Fueron muy pocos los entrevistados que en otras oportunidades habían brindado testimonio, o habían sido entrevistados previamente. En algún caso fue la causa que investiga los delitos cometidos contra las personas detenidas ilegalmente en "300 Carlos", cuyo testimonio tuvo que ver con una denuncia penal". O breves entrevistas escritas para periódicos zonales, prensa partidaria o portales de internet. Michael Pollak afirma que el silencio, lejos de conducir al olvido, se convierte en la resistencia que una sociedad civil impotente opone al exceso de discursos oficiales, esperando la hora de la verdad y la redistribución de las cartas en ideológicas y políticas. Además de la hora de la verdad y la coyuntura política propicia para la emergencia de esos recuerdos existen otras dimensiones a tener en cuenta. Quienes testimonian no siempre han encontrado una escucha receptiva de esas experiencias, ya que no sólo resultan temas difíciles de abordar para el propio testimoniante sino que han sido también socialmente acallados por décadas (Bacci, Oberti, y Skura, 2010).

\footnotetext{
No tenía ni idea que iba a poder decir tantas cosas como las que dije ¡Vaya a saber los disparates! (risas). Para mí fue un gusto, les agradezco que me hayan escuchado, me hayan tenido esa paciencia... Y esta es mi visión, subjetiva por supuesto, de todos mis andares... por este mundo. Claro, quedan muchas cosas para atrás, he tratado de dejar las negativas últimamente... que me las cuente otro (risas). Y ta, y punto, muchas gracias. (Omar Mir, entrevistado el Septiembre de 2017)
}

Existe también la voluntad de silencio, de atesorar las huellas para cuidar de los otros, “(...) como expresión del deseo de no herir ni transmitir sufrimientos. Hay otra lógica en el silencio. Para relatar sufrimientos, es necesario encontrar del otro lado la voluntad de escuchar (Laub, 1992b; Pollak, 1990 en Jelin, 2001).

Graciela es la compañera de Leopoldo Correa, una de las personas que entrevisté, en el primer encuentro previo a la entrevista de Leopoldo donde estuvimos los tres, ella intervino en varias oportunidades, aclarando que su compañero era un poco olvidadizo, y recordándome que aún le costaba hablar del tema. Entre el primer encuentro y el día la entrevista - que fue realizada en su casa en el departamento de Maldonado- Graciela me dijo que ella tenía un texto de su autoría con su propia experiencia como presa política. Continuamos en contacto, por algunas actividades desarrolladas en el MUME y mensajes de saludos por fin de años y demás (Más adelante desarrollare el tema del vínculo entrevistador entrevistado). En el momento en que se comenzó con la subserie "familiares", la contacté con la idea de hacer un "primer encuentro" para llevar a cabo la entrevista, ella fue postergándome la fecha, por razones de salud primero, por falta de tiempo después. Hasta que finalmente logró transmitirme la angustia que le generaba el volver a hablar de su paso por la cárcel, y me advirtió el deseo de no querer hacerme daño con su relato. De acuerdo con Pollak existe en las memorias individuales el temor a ser incomprendido. El encontrar a otros con capacidad de escuchar es central en el proceso de quebrar silencios.

\section{Memorias Políticas}

Partiendo de la definición de testimonio desarrollada por Susana Skura podemos identificar dos dimensiones: por un lado la transmisión como una forma de pasaje de lo privado a lo público; y por otro 
lado la importancia de la escucha. Sin embargo me gustaría destacar una tercera dimensión, que resulta inherente a destacar cuando tratamos con memorias de violencia política, y es justamente la dimensión política de las memorias. Al ingresar a la esfera pública (8) el testimonio se vuelve un hecho político, ya no se trata de memorias espontáneas, la memoria política busca intervenir en el mundo social, denunciando, y discutiendo la realidad política, social y jurídica. El testimonio permite a los entrevistados posicionarse como agentes y distanciarse del lugar de víctimas. Los entrevistados no niegan su identidad política ni su militancia, por lo que prefieren -en su mayoría- identificarse como sobrevivientes.

Gustavo Mora es un médico psiquiatra jubilado, militante PVP durante su juventud y al momento de ser detenido, actualmente forma parte de la Comisión por Memoria Verdad y Justicia en Mercedes. Algunos años después de haber salido de prisión escribió un libro "Inaugurar el Alba", en una nota realizada por un portal de internet él explica: "el texto tiene que ver con mantener viva la memoria (...)". Al final de nuestra primera sesión de entrevista en Mayo de este año, le pregunté a qué se refería con mantener viva la memoria:

Creo que hay que mantener viva la memoria, en última instancia, para entender o darle cabal entidad - este un pensamiento filosófico, ideológico y político mío - de la crudeza de la lucha de clases. (...) Es tan cruda que no nos podemos distraer, es tan cruda que no podemos ser ingenuos (...). Ellos no se distraen, no te permiten, no te dan pie a que vos "estribes" - como dicen los gauchos-, te desestriban al rato nomás y... volvemos para atrás. (...) Sobre todo para eso, para dar cuenta de lo serio y extremada que es la lucha de clases. Y mañana, yo no creo que "Nunca Más", yo no creo. Lo digo, lo fomento, lo propagandeo pero si en algún momento es necesario puede pasar de vuelta ¿por qué? porque es enserio. El capitalismo no puede permitir la chance de que se generen países o sociedades que tengan fundamentos distintos o contrapuestos al capitalismo. Mantener la memoria no para victimizar sino, para entender que esto es una lucha política encarnizada, la memoria como herramienta política. (Gustavo Mora, entrevistado en Mayo de 2018)

De esta manera Gustavo vuelve sobre la problemática de la victimización, si bien él entiende que es necesario dar cuenta de las prácticas y políticas sistemática de represión ejercidas durante la última dictadura militar, también remarca su lugar de agente de transformación. Fue detenido, torturado y encarcelado por motivos políticos, y esa identidad política no desaparece en el relato. La memoria es para Gustavo una herramienta política en la medida que le permite traer a la arena pública la denuncia, pero también la advertencia.

\section{Conclusiones}

Elizabeth Jelin establece una distinción muy importante en los procesos de memorias: lo activo y lo pasivo. La existencia de archivos, centros de documentación, huellas del pasado almacenadas en distintos tipos de soportes no garantizan su evocación. "En la medida en que son activadas por el sujeto, en que son motorizadas en acciones orientadas a dar sentido al pasado, interpretándolo y trayéndolo al escenario del drama presente, esas evocaciones cobran centralidad en el proceso de interacción social.” (Jelin, 2001, p. 7)

Desde que comencé mi trabajo como entrevistadora, y en mayor medida mientras realizaba este trabajo me preguntó acerca de la funcionalidad del Archivo Oral en término políticos y de transmisión. Sin dudas este fragmento de Elizabeth Jelin me conduce a pensar en este proyecto como una memoria pasiva. Tratando de esquivar los análisis lineales, entiendo y resalto el valor del archivo, como un "lugar de memoria", una forma de denuncia y en definitiva como una manera de propiciar que tenga lugar un discurso que -hasta ahorapudo no tenerlo.

Sin embargo considero que es necesario lograr a futuro la manera de que esos testimonios no sean solamente un documento de consulta para la academia, para producir exclusivamente más estudios sociales sobre las memorias. Una de nuestras urgencias como equipo es la edad, la muerte de los testimoniantes nos sobrevuela. 
Sin dudas tomar testimonios de los protagonistas de nuestra historia recientes es urgente, pero también es urgente activar esas memorias fuera de las fronteras de la academia. Creo que el desafío es comenzar a construir alternativas para que esos testimonios no sean sólo documentos, en un país donde dos veces la sociedad civil eligió no derogar las leyes de impunidad pero, donde las memorias subalternas siguen encontrado la oportunidad de pronunciarse.

\section{REFERENCIAS}

Achugar, H. (2003). El lugar de la memoria, a propósito de monumentos (motivos y paréntesis). En E. Jelin, y V. Langland (Ed.), Monumentos, memoriales y marcas territoriales (pp. 191-221). Buenos Aires: Siglo XXI.

Allier Montaño, E. (2008). Los Lieux de mémoire: una propuesta historiográfica para el análisis de la memoria. Historia $y$ Grafia, (31), 165-192.

Bacci, C., Oberti, A., Skura, S. y Capurro Robles, M. (2014). Entre lo público y lo privado: los testimonios sobre la violencia contra las mujeres en el terrorismo de Estado. Clepsidra. Revista Interdisciplinaria de Estudios sobre Memoria, 1(1), 122-139

Bacci, C., Oberti, A. y Skura, S. (2012). La vitalidad del testimonio Acerca de la experiencia del Archivo Oral en Memoria Abierta. Revista Cambios y Permanencias, (3), 34-48.

Bacci, C., Oberti, A. y Skura, S. (2010). Es ahora. El testimonio acerca del pasado reciente argentino. VI Jornadas de Sociología de la UNLP. Recuperado de: http://www.memoria.fahce.unlp.edu.ar/trab_eventos/ev.5045/ev.504 5.pdf

Candau, J. (2002). Antropología de la memoria. Buenos Aires: Ediciones Nueva Visión

Crespo, C. (2011). De pasados presentes: hacia una etnografía de archivos. Revista Colombiana de Antropología, 47(1), 69-90.

Garaño, S. (2009). Sentidos y prácticas de la "resistencia" memorias de ex presas y presos políticos durante la última dictadura militar argentina (1976-1983). Historia, antropología y fuentes orales, (41), 5-24.

GIAF (2015). Investigaciones Antropológicas sobres detenidos-desaparecidos en la última dictadura cívico-militar. Informe de Actividades Año 2013-2014. Recuperado de: https://sitiosdememoria.uy/sites/default/files/2020-0 2/INFORME\%2BDE\%2BACTIVIDADES\%2BGIAF\%2B2013-2014.pdf

Guglielmucci, A. (2013). La consagración de la memoria. Una etnografía acerca de la institucionalización de recuerdo sobre los crimenes de Estado en la Argentina. Buenos Aires: Editorial Antropofagia

Jelin, E. (2001). Los trabajos de la memoria. España: Siglo XXI.

Jelin, E. (2008). Respuestas políticas al pasado en el presente: las cuestiones sin saldar. En A. Rico (comp.), Historia reciente. Historia en discusión (pp. 91-111). Montevideo: PNUDMEC- FHCE- CEIU

Lavabre, M. (2012). Sobre el peso y la elección del pasado, Una lectura crítica de El síndrome de Vichy. Aletheia. Revista de la Maestría en Historia y Memoria de la Fahce, 3(5), 1-9.

Levi, P. (2000). Los hundidos y los salvados. Barcelona: Muchnick Editores.

López Mazz, J. (coord.) (2007). Investigación Arqueológica sobre Detenidos Desaparecidos, Tomo V. Montevideo: Presidencia República Oriental del Uruguay.

Nora, P. (1984). Les Lieux de Mémoire (pp. XVII-XLIL). Traducción para uso exclusivo de la cátedra Seminario de Historia Argentina Prof. Femando Jumar C.U.R.Z.A., Universidad Nacional del Comahue.

Nora, P. (1998). La aventura de Les lieux de mémoire. Ayer (Asociación de historia contemporánea), (32), 17-34.

Pollak, M. (2006). Memoria, olvido, silencio. La producción social de identidades frente a situaciones límite. La Plata: Editorial Al Margen

Ricoeur, P. (2003). La historia, la memoria, el olvido. Madrid: Trotta.

Skura, S. (2017). Memoria, verdad y transmisión oral en el testimonio y la entrevista abierta antropológica. En A. Domínguez Mon (comp.), Trabajo de campo etnográfico: prácticas y saberes: metodología y técnicas de la 
investigación de campo (pp. 147-176). Ciudad Autónoma de Buenos Aires: Editorial de la Facultad de Filosofía y Letras Universidad de Buenos Aires.

\section{Notas}

1 https://www.lanacion.com.ar/788817-no-hay-que-confundir-memoria-con-historia-dijo-pierre-nora.

2 Entrevista a Peter Kroch de la Asociación de Amigos del MUME, para el audiovisual del archivo oral - año 2017.

3 Dentro del Cuadro de Clasificación Documental de la Intendencia de Montevideo, el Archivo Oral de la Memoria surge como Subfondo subordinado, dentro del subfondo Documentación de colecciones museográficas (UY-IMO-DM) del Fondo Intendencia de Montevideo. Se comenzó definiendo una primera serie denominada Centro Clandestino de Detención y Tortura 300 Carlos - Infierno Grande y una subserie correspondiente a Sobrevivientes del Centro Clandestino de Detención y Tortura 300 Carlos. La subserie en este caso, corresponde a la categoría definida para la realización de la entrevista.

4 Es importante señalar que este texto fue escrito durante la primera mitad de 2018, en Agosto de 2019 el acervo está compuesto casi de 100 entrevistas.

5 Documento actualizado. Ley N 18596 Promulgación: 18/09/2009 Publicación: 19/10/2009Registro Nacional de Leyes y Decretos: Tomo: 1Semestre:2Año:2009.

6 A propósito de esto, es interesante destacar la diferencia entre los testimonios brindados en este tipo de entrevistas y los testimonios en el marco de una causa judicial. Como se mencionó más arriba,distintos autores (Jelin, Pollak, Skura, Oberti, Bacci) han trabajo de la relevancia de la escucha. La entrevista como universo dialógico, relacional e intersubjetivo proporciona una escucha diferente a la que pueda darse en un marco jurídico. "Creemos que la particularidad de este tipo de abordaje respecto del judicial, por ejemplo, se evidencia tanto en términos de la forma como de sus contenidos y de la interlocución que genera no sólo en el momento de la entrevista, sino también con quienes luego lo consultarán: ver y oír el relato de la experiencia sobre la violencia requiere una escucha atenta y cuidada. Este cuidado comienza antes del testimonio y se reitera cada vez que se accede a él."(Bacci, Capurro Robles, Oberti y Skura, 2014, p. 124)

7 "El autor define la esfera pública como un espacio social donde los flujos comunicacionales se condensan en opiniones públicas que ejercen influencia en la circulación del poder político (Habermas, 1997, p. 92). En la esfera pública los participantes "asumen posiciones" y "uniones potenciales" de diálogo o de opinión. La esfera pública no es una institución, ni una organización, pues no constituye una estructura normativa capaz de diferenciar competencias y roles sociales. Tampoco es un sistema, porque se caracteriza por tener “horizontes abiertos, permeables y desplazables”. Es más bien una red adecuada para la comunicación de contenidos, toma de posiciones y opiniones, y está asociada tanto a la acción de movimientos sociales, como a ámbitos considerados privados, donde a través los medios de comunicación, por ejemplo, los sujetos son convocados a tomar posicionamientos políticos.” (Lifschitz, 2012, p. 6). 